\title{
A study on static structural of non-rotor unmanned aerial vehicle
}

\author{
Yu-Lan Chen ${ }^{1, a}$, Jiunn Fang ${ }^{2}$, Yau-Ren Shiau ${ }^{3}$ and Wei-Chun Hung ${ }^{1}$ \\ ${ }^{1}$ Ph.D. Program of Mechanical and Aeronautical Engineering, Feng Chia University, Taichung 407, Taiwan, ROC \\ ${ }^{2}$ Department of Aerospace and Systems Engineering, Feng Chia University, Taichung 407, Taiwan, ROC \\ ${ }^{3}$ Department of Industrial Engineering and Systems Management, Feng Chia University, Taichung 407, \\ Taiwan, ROC
}

\begin{abstract}
Multi-rotor unmanned aerial vehicles (UAVs) have become common in recent years, but non-rotor UAVs are still relatively rare. This study used an aerodynamic model to replace the multi-rotor design concept and examine load bearing capabilities, specifically for delivery of medical goods by non-rotor UAV. We use static structural simulations for static analysis and fatigue analysis to investigate the capabilities of different structural materials. The simulation results combined fatigue strength verifications, structural safety factor calculations, and finite element analyses to calculate parameters like total deformation, stress ratios, and strain magnitudes to analyze structural fatigue life. The analyses indicated that the factors of safety and fatigue lifetimes of two structural materials far exceeded standard values. They can be used to optimize designs that prevent plastic deformation and breakage. Time and money are saved in the research and development process by carrying out these calculations and static analyses of physical properties before prototypes are actually built.
\end{abstract}

\section{Introduction}

In recent years, multi-rotor UAVs controlled with the help of GPS, inertial navigation, and remote control systems have been widely used in aerial photography and videography for environmental monitoring, weather observations, etc. They are more convenient and cheaper than full-size helicopters or reconnaissance aircraft.

There is a plethora of commercially available, single or multi-rotor UAVs with increasingly sophisticated automatic control and monitoring systems that cover a vast array of potential mission capabilities. However, whether UAVs can be used to deliver medical supplies when natural disasters such as earthquakes, landslides, and floods knock out ground transportation, has become a key question in rescue operations.

Most UAVs today have multiple rotors, and in the presence of a cargo carrying function, their cargoes are generally suspended below the aircraft. In this study, aerodynamic models of non-rotor plate load UAVs are used to replace the more common multi-rotor design. In order to reduce research and development time and improve product quality and reliability, static and fatigue analyses are carried out using ANSYS structural simulations.

\footnotetext{
${ }^{\mathrm{a}}$ Corresponding author : wearefamily999@gmail.com
} 
In the Industry 4.0 era, new and improved observation and reconnaissance systems are being constantly developed and brought out on to the market. UAVs are playing an increasingly important role in the prevention and control of environmental disasters and severe weather events triggered by global climate change.

Meteorological sensors aboard UAVs were able to obtain which data of air temperature, pressure, relative humidity, wind speed, etc. during missions at the outskirts of Typhoon Sinlaku [1]. Archaeological surveys carried out with LiDAR data and UAV-assisted photographic marking were faster and cheaper than traditional methods. UAVs also enabled the construction of 3D models of mining sites and hydraulic systems [2]. Moreover, UAVs can provide perspectives from various altitudes and angles to aid in the detection and tracking of vehicles. Being able to verify three significant characteristics of images: edges; optical flow; and local feature points, they assist in improving accuracy and enable significant improvements in vehicle identification and tracking capabilities [3].

Before a product is launched in the market, a prototype is made. However, in addition to the money and time required to make the prototype, tests and analyses must be performed to guarantee its physical capabilities and design effectiveness. Nowadays, computer aided engineering (CAE) plays an important role in that process. In particular, CAE is used for: 1) looking at stress with static and dynamic finite element analyses (FEA); 2) thermal and fluid dynamics analyses and calculations (computational fluid dynamics or CFD); 3) motion and power analyses in multibody mechanics; 4) finite element analysis and boundary element methods in acoustic analyses; 5) simulation of mechanical activities in manufacturing execution systems (MES), etc. Software for these applications included ANSYS, CATIA, NASTRAN, SolidWorks and PTC Creo (Pro/Engineer).

Fishing ships that spend long periods of time at sea need excellent freezers with low power consumption. At the beginning of the design phase of the refrigeration deck, SolidWorks was used to set up a model of a refrigerator. Then, a mesh was created for the model using ANSYS Workbench, so as to calculate the steady state heat transfer rate through the walls of the refrigerator, find an optimal insulation configuration, and determine its effectiveness [4]. In order to determine the dynamic stability of the compressor and reduce wear and tear, a CAE model with constraints was set up to calculate parameters, estimate overall inertia, moments of inertia, contact forces between the rotor and the casing, and dynamic stability. Every parameter of interest could be tested and analyzed using such a simulation. This way, it was possible to see how a dual plane dynamically balanced design improved on the original design [5]. The flux patterns, flux density, and field intensity in magnetic levitation systems used for mass transit were determined using finite element methods. They revealed the working forces on U type actuators and I type rails under various working conditions [6]. An important aspect in loudspeaker design is magnetic field patterns. Models were constructed in SolidWorks to demonstrate the actual magnetic field distribution in loudspeakers. Then, by executing an ANSYS Workbench simulation, it was possible to solve for electrical current density, overall magnetic flux density, and direction of magnetic field. The use of ANSYS Workbench in the verification and optimization process allowed for a quick analysis of the magnetic system, and helped in arriving at detailed conclusions about the comparative magnetic induction strength of sound coils in different positions [7]. In the design of treadmills, in order to reduce the possibility of injury due to poor jogging habits, finite element analysis (FEA) is used in static and dynamic models to compare the effectiveness of the equipment's weight sensors at measuring reaction forces on the user's feet in various positions. Highly integrated embedded systems give treadmills the required responsiveness to enable a new level of interaction between the treadmill and the runner, based on reaction force monitoring [8]. By using ANSYS Parametric Design Language (APDL) to analyze usable structures, we discovered fatigue fractures in UAV landing gear, contour effectiveness, and the stress and fracture growth rates associated with fatigue fractures. By performing static analyses, we located critical regions [9]. 


\section{Methods}

This study used PTC Creo to build a geometric model and set simulation conditions like materials, loads, constraints, mesh, etc. in the non-rotor aerodynamic model. With a focus on load characteristics, the model was imported into ANSYS for structural statics and fatigue analyses [10-14].

\subsection{Creation of the geometric model}

The Bernoulli Principle, which states that when the velocity of a fluid increases, its pressure decreases, is widely used in aeronautical engineering. Flying machines push air downwards to create lift. When the force of lift is greater than the machine's weight, the machine ascends. Optimal design seeks to maximize or minimize the value of an objective function within the range of the set constraints. These constraints are determined by practical demands on performance. For mechanical engineers, design optimization means that geometric parameters like lengths, thicknesses, radii, and nodes are variables. These parameters along with principles followed in mechanics, such as applied forces, are combined to optimize stress distributions and deformations $[15,16]$.

This study constructed a 3D aerodynamic model of the non-rotor UAV. As shown in Fig. 1, it comprises a $380 \mathrm{~mm}$ diameter and $102.87 \mathrm{~mm}$ height plate for carrying loads, an engine compartment, and 4 jet intakes and exhaust valves. Using this model, the static structural analysis was carried out.

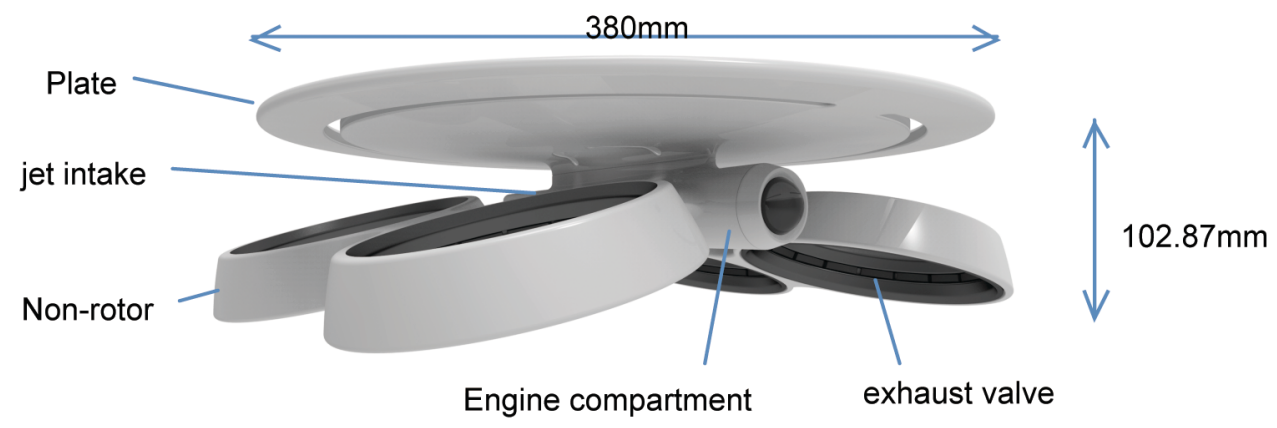

Figure 1. Non-rotor UAV model.

\subsection{Setting simulation conditions}
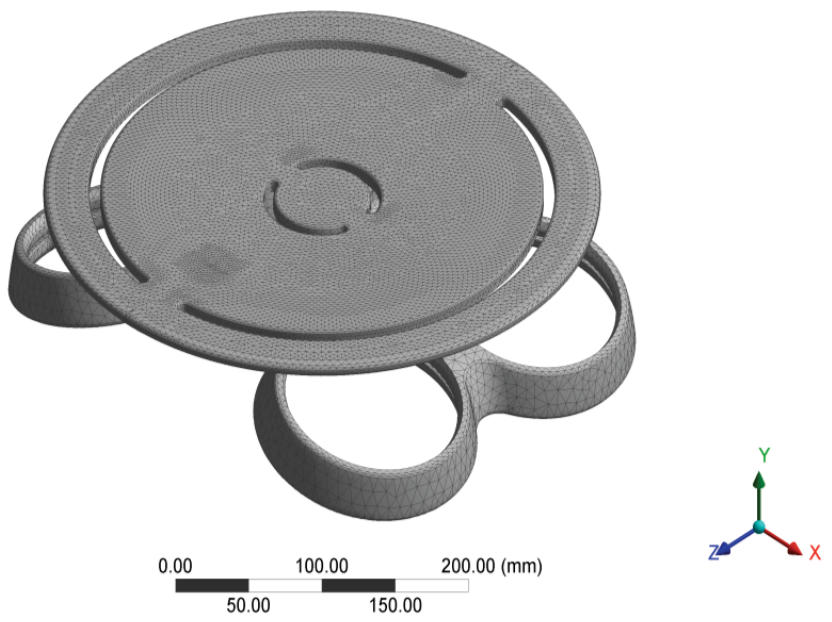

Figure 2. Mesh model. 
The materials selected include: Aluminum Alloy, which is widely used in transportation, household electronics, construction, and mechanical hardware industries for its rigidity; and titanium alloy, which is used in the aviation, automobile, and biomedical equipment industries. Aluminum has a high strength to weight ratio and is commonly used in structural applications. Titanium is strong, light, highly resistant to fatigue and corrosion, and non-magnetic. It can also tolerate temperature fluctuations because of its low coefficient of thermal expansion (Table 1). Aluminum alloy and titanium alloy are selected based on the above characteristics and advantages as the structural materials for UAV.

In the mesh division and calculation settings, physical preferences were set to mechanical. The solver target used APDL, with relevance being set to 100. In the relevance center, the parameter was set to fine, while smoothing was set to medium and mesh transition to fast. Accurate analyses and modeling were of primary concern (Figure 2.).

Table 1. Parameters and properties of materials.

\begin{tabular}{|c|c|c|}
\hline Properties & Aluminum Alloy & Titanium Alloy \\
\hline Density & $2.77 \mathrm{e}-006 \mathrm{~kg} \mathrm{~mm}^{\wedge}-3$ & $4.62 \mathrm{e}-006 \mathrm{~kg} \mathrm{~mm}^{\wedge}-3$ \\
\hline Coefficient of Thermal Expansion & $2.3 \mathrm{e}-005 \mathrm{C}^{\wedge}-1$ & $9.4 \mathrm{e}-006 \mathrm{C}^{\wedge}-1$ \\
\hline Specific Heat & $8.75 \mathrm{e}+005 \mathrm{~mJ} \mathrm{~kg}^{\wedge}-1 \mathrm{C}^{\wedge}-1$ & $5.22 \mathrm{e}+005 \mathrm{~mJ} \mathrm{~kg}^{\wedge}-1 \mathrm{C}^{\wedge}-1$ \\
\hline Thermal Conductivity & - & $2.19 \mathrm{e}-002 \mathrm{~W} \mathrm{~mm}^{\wedge}-1 \mathrm{C}^{\wedge}-1$ \\
\hline Resistivity & - & $1.7 \mathrm{e}-003 \mathrm{ohm} \mathrm{mm}$ \\
\hline Reference Temperature & $22{ }^{\circ} \mathrm{C}$ & $22{ }^{\circ} \mathrm{C}$ \\
\hline Young's Modulus & $71000 \mathrm{MPa}$ & $96000 \mathrm{MPa}$ \\
\hline Poisson's Ratio & 0.33 & 0.36 \\
\hline Bulk Modulus & $69608 \mathrm{MPa}$ & $1.1429 \mathrm{e}+005 \mathrm{MPa}$ \\
\hline Shear Modulus & $26692 \mathrm{MPa}$ & $35294 \mathrm{MPa}$ \\
\hline Temperature & $\mathrm{Yes}$ & $\mathrm{Yes}$ \\
\hline Shear Angle & $\mathrm{No}$ & $\mathrm{No}$ \\
\hline Degradation Factor & $\mathrm{No}$ & $930 \mathrm{MPa}$ \\
\hline Tensile Yield Strength & $280 \mathrm{MPa}$ & $930 \mathrm{MPa}$ \\
\hline Compressive Yield Strength & $280 \mathrm{MPa}$ & $1070 \mathrm{MPa}$ \\
\hline Tensile Ultimate Strength & $310 \mathrm{MPa}$ & 0 \\
\hline Compressive Ultimate Strength & 0 & \\
\hline
\end{tabular}

A Force_Plate: $50 . \mathrm{N}$

B Force_non-rotor: $50 . \mathrm{N}$

C Fixed Support
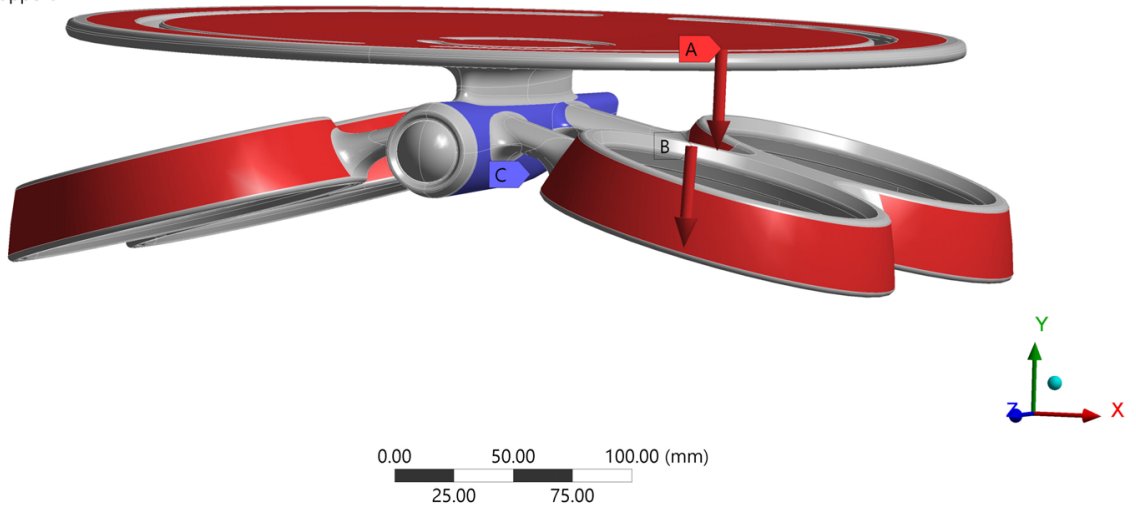

Figure 3. Loads and constraints. 
For constraints, we selected fixed support with the engine compartments (Fig. 3C) fixed to constrain their Ux, Uy, and Uz degrees of freedom. The cargo platform (Fig. 3A) load was set to $50 \mathrm{~N}$, with the force direction being downwards. The loads applied to the four airflow vents (Fig. 3B) were $50 \mathrm{~N}$. Even here, the force direction was downwards.

\section{Results and discussion}

The material analysis data derived by importing the parameters above is shown in Table 2, they are Nonlinear Effects and Thermal Strain Effects, Bounding Box Length X 386.86 mm, Length Y 102.87 $\mathrm{mm}$, Length Z $380.66 \mathrm{~mm}$, Volume $1.6567 \mathrm{e}+006 \mathrm{~mm}^{3}$, Mass $4.5889 \mathrm{~kg}$ and $7.6538 \mathrm{~kg}$, Centroid X 5.3181e-002 mm, Centroid Y $15.743 \mathrm{~mm}$, Centroid Z $2.9233 \mathrm{~mm}$, Nodes 318211, Elements 186514, and None Mesh Metric etc.. Static structural analysis revealed the deformation occurring upon application of stresses. This led to the structural statics and fatigue analysis simulation results, in Table 3, as described in 3.1 Static Analysis.

Table 2. Material analysis.

\begin{tabular}{|c|c|c|c|}
\hline \multicolumn{2}{|c|}{ Assignment / Item } & Aluminum Alloy & Titanium Alloy \\
\hline \multirow{3}{*}{ Material } & Nonlinear Effects & Yes & Yes \\
\cline { 2 - 4 } & Thermal Strain Effects & Yes & Yes \\
\hline \multirow{3}{*}{$\begin{array}{c}\text { Bounding } \\
\text { Box }\end{array}$} & Length X & $386.82 \mathrm{~mm}$ & $386.82 \mathrm{~mm}$ \\
\cline { 2 - 4 } & Length Y & $102.87 \mathrm{~mm}$ & $102.87 \mathrm{~mm}$ \\
\cline { 2 - 4 } & Length Z & $380.66 \mathrm{~mm}$ & $380.66 \mathrm{~mm}$ \\
\hline \multirow{5}{*}{ Properties } & Volume & $1.6567 \mathrm{e}+006 \mathrm{~mm}^{3}$ & $1.6567 \mathrm{e}+006 \mathrm{~mm}^{3}$ \\
\cline { 2 - 4 } & Mass & $4.5889 \mathrm{~kg}$ & $7.6538 \mathrm{~kg}$ \\
\cline { 2 - 4 } & Centroid X & $-5.3181 \mathrm{e}-002 \mathrm{~mm}$ & $-5.3181 \mathrm{e}-002 \mathrm{~mm}$ \\
\cline { 2 - 4 } & Centroid Y & $15.743 \mathrm{~mm}$ & $15.743 \mathrm{~mm}$ \\
\cline { 2 - 4 } & Centroid Z & $2.9233 \mathrm{~mm}$ & $2.9233 \mathrm{~mm}$ \\
\cline { 2 - 4 } & Moment of Inertia Ip1 & $37896 \mathrm{~kg} \cdot \mathrm{mm}^{2}$ & $63205 \mathrm{~kg} \cdot \mathrm{mm}{ }^{2}$ \\
\cline { 2 - 4 } & Moment of Inertia Ip2 & $78201 \mathrm{~kg} \cdot \mathrm{mm}^{2}$ & $1.3043 \mathrm{e}+005 \mathrm{~kg} \cdot \mathrm{mm}{ }^{2}$ \\
\cline { 2 - 4 } & Moment of Inertia Ip3 & $48333 \mathrm{~kg} \cdot \mathrm{mm}^{2}$ & $80613 \mathrm{~kg} \cdot \mathrm{mm}^{2}$ \\
\hline \multirow{5}{*}{ Statistics } & Nodes & 318211 & 318211 \\
\cline { 2 - 4 } & Elements & 186514 & 186514 \\
\cline { 2 - 4 } & Mesh Metric & None & None \\
\cline { 2 - 4 } & & & \\
\hline
\end{tabular}

Table 3. Structural statics and fatigue analyses.

\begin{tabular}{|c|c|c|c|}
\hline \multicolumn{2}{|c|}{ Item } & Aluminum Alloy & Titanium Alloy \\
\hline \multirow{2}{*}{ Total Deformation } & Min. & $0 \mathrm{~mm}$ & $0 \mathrm{~mm}$ \\
\cline { 2 - 4 } & Max. & $5.078 \mathrm{e}-002 \mathrm{~mm}$ & $3.7671 \mathrm{e}-002 \mathrm{~mm}$ \\
\hline \multirow{2}{*}{ Equivalent Elastic Strain } & Min. & $1.3043 \mathrm{e}-011 \mathrm{~mm} / \mathrm{mm}$ & $4.3847 \mathrm{e}-010 \mathrm{~mm} / \mathrm{mm}$ \\
\cline { 2 - 4 } & Max. & $3.243 \mathrm{e}-005 \mathrm{~mm} / \mathrm{mm}$ & $3.85 \mathrm{e}-005 \mathrm{~mm} / \mathrm{mm}$ \\
\hline \multirow{2}{*}{ Equivalent (von-Mises) Stress } & Min. & $7.9588 \mathrm{e}-007 \mathrm{MPa}$ & $4.1547 \mathrm{e}-005 \mathrm{MPa}$ \\
\cline { 2 - 4 } & Max. & $2.2943 \mathrm{MPa}$ & $3.6813 \mathrm{MPa}$ \\
\hline Safety Factor & Min. & $>15$ & $>15$ \\
\hline Life & Min. & $1 . \mathrm{e}+008$ cycles & Not applicable \\
\hline
\end{tabular}




\subsection{Static Analysis}

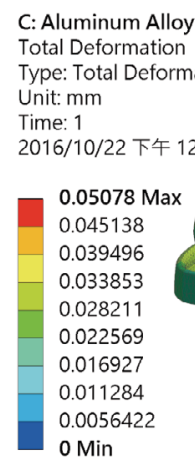

(1)
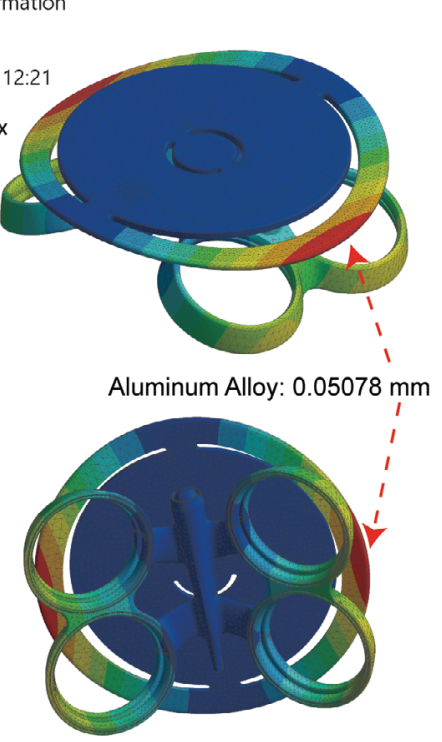

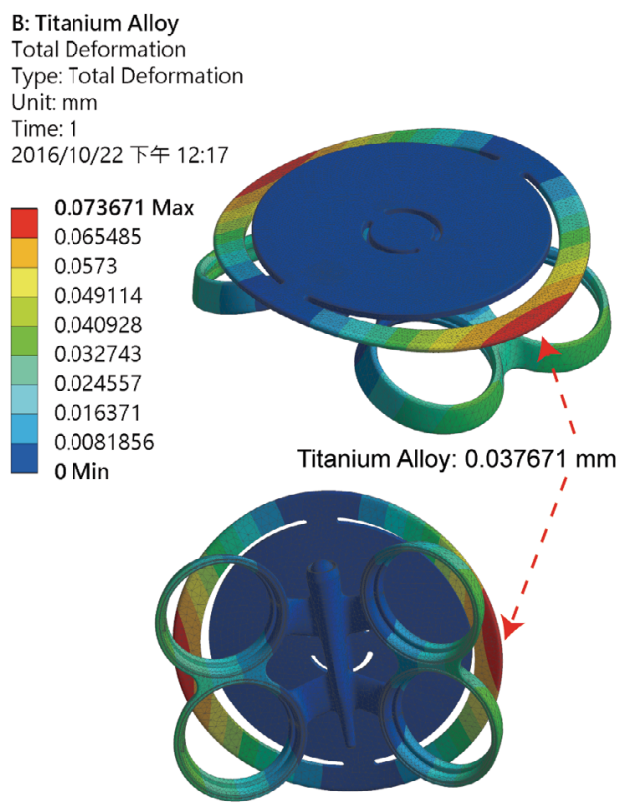

Figure 4. Total deformation (Top view and bottom view)
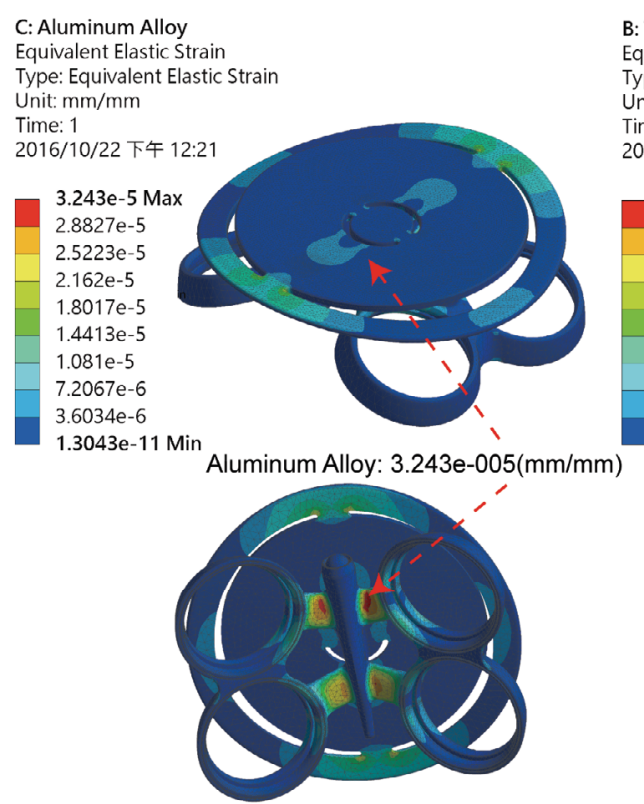

B: Titanium Alloy

Equivalent Elastic Strain

Type: Equivalent Elastic Strain

Unit: $\mathrm{mm} / \mathrm{mm}$

Time: 1

2016/10/22 下午 12:15

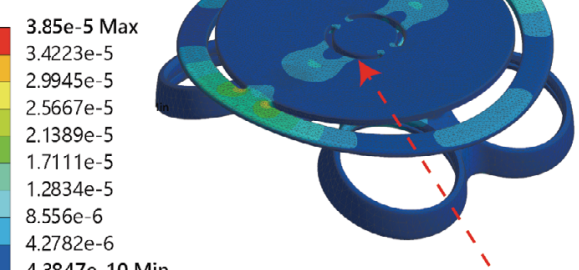

4.3847e-10 Min

Titanium Alloy: 3.85e-005 (mm/mm)

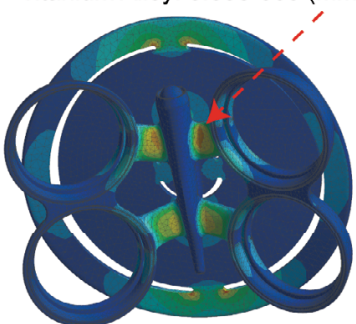

Figure 5. Equivalent elastic strain (Top view and bottom view)

Static analysis can confirm the most likely location of material fatigue. The $50 \mathrm{~N}$ force acting on the cargo platform and the $50 \mathrm{~N}$ combined forces acting through the airflow ports are shown in Figure 3. The structure itself is composed of $4.5889 \mathrm{~kg}$ of aluminum alloy or $7.6538 \mathrm{~kg}$ of titanium alloy. Total deformation under load and maximum stresses are in the curved areas. Elastic deformation in the aluminum alloy was 5.078e-002 mm and in the titanium alloy, it was 3.7671e-002 mm. From Fig. 4, we can see that the location of maximum deformation is at the free edges of the cargo platform and 
not at the point where the weight of the cargo acts. This met the design goals. The maximum equivalent elastic strain was 3.243e-005 in the aluminum model and 3.85e-005 in the titanium model (Fig. 5). Maximum equivalent stress was $2.2943 \mathrm{MPa}$ in the aluminum model and $3.6813 \mathrm{MPa}$ in the titanium model (Fig. 6). If the maximum elastic stress values are lower than the materials' yield stresses with safety factors of 1.25 , plastic deformation and breakage can be avoided.

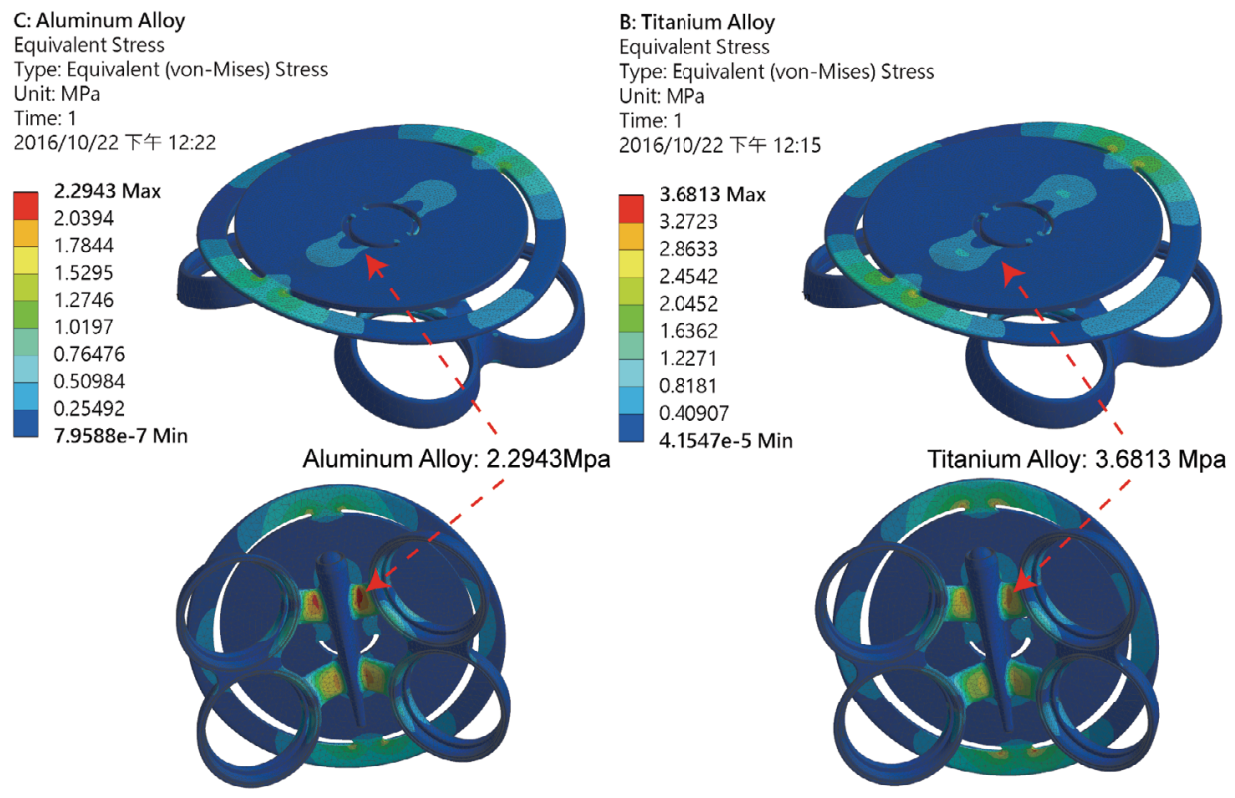

Figure 6. Equivalent Stress (Top view and bottom view)

\subsection{Fatigue Analysis}

\section{Safety Factor \\ Time: 1

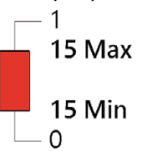

C: Aluminum Alloy

Type: Safety Factor

2016/10/22 下午 12:23
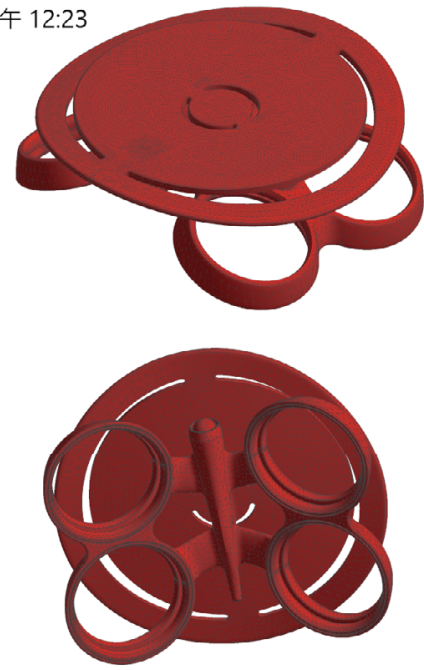

Figure 7. Safety factor (Top view and bottom view)
B: Titanium Alloy

Safety Factor

Type: Safety Factor

Time: 1

2016/10/22 下午 12:18
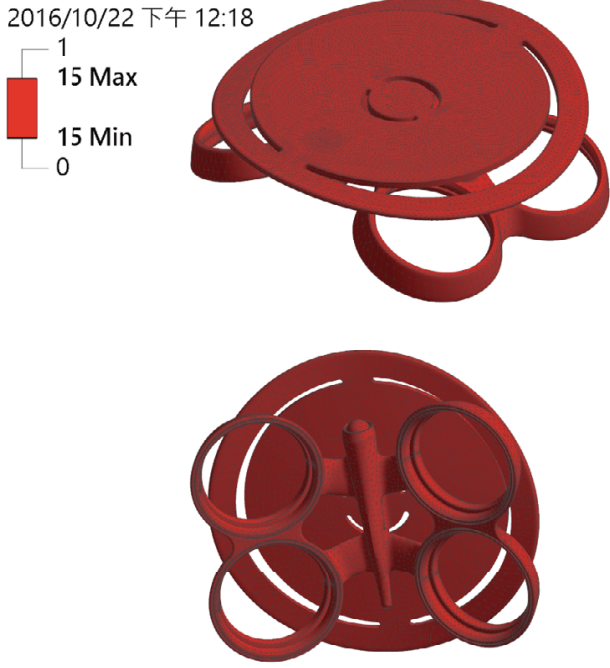
In general, minimum safety factors are in the range of $1.25-3.0$. In the aerospace industry, safety factors must be greater than 1.25 and must be accompanied by strict quality control measures to guarantee the operational safety of the components. According to the results of this study, both materials have factors of safety exceeding 15 (Fig. 7). Fatigue life analysis results as shown in Fig. 8 were obtained using stress intensity factor and mesh distribution. Aluminum alloy has a fatigue lifetime of 100,000,000 cycles. When the repeated loading and unloading of titanium alloy does not cause strain above the fatigue minimum, its fatigue lifetime remains unaffected [17].

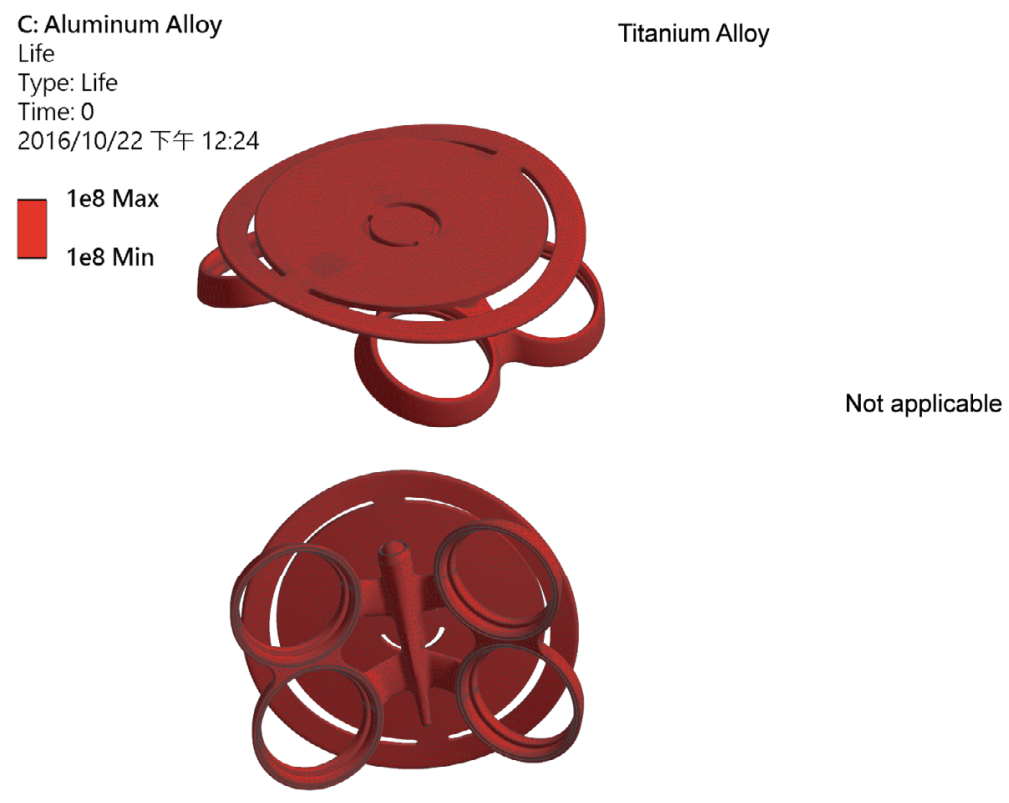

Figure 8. Lifetime of Material Fatigue (Top view and bottom view)

\section{Conclusions}

The static structural analysis simulation in this research focused on discussing factors of safety and fatigue lifetime of non-rotor UAVs. In the comparative analysis of aluminum alloy and titanium alloy structures, the design load was $50 \mathrm{~N}$ with constraints and mesh designs used being identical. An aerodynamic model was used in place of a multi-rotor UAV in the simulation. With load bearing being the vehicle's objective, fatigue intensity verification, structural factor of safety calculations, and finite element analyses were carried out to obtain the total deformation for the aluminum alloy this amounted to $5.078 \mathrm{e}-002 \mathrm{~mm}$ and in case of titanium alloy $3.7671 \mathrm{e}-002 \mathrm{~mm}$. Equivalent stresses for aluminum and titanium alloys were $2.2943 \mathrm{MPa}$ and $3.6813 \mathrm{MPa}$, resp. Equivalent strain magnitudes were $1.3043 \mathrm{e}-011$ - 3.243e-005 for aluminum and 4.3847e-010 - 3.85e-005 for titanium, analysis data could be show that can avoid plastic deformation and breakage. These parameters were used to analyze fatigue lifetimes, analyses show that both materials have safety factors and fatigue lifetimes that by far exceed current standards.

From the above analysis and data that suitable structural and materials via application of static structure analysis can be known in advance and avoid plastic deformation and breakage and can be used for optimal design. By calculating and testing the physical properties of the vehicle before actually making a prototype, it is possible to save time and money that would otherwise be wasted on structural redesign. This makes the research and development process more efficient. 
In future projects, it is recommended that the engine compartment be designed in more detail. For example, blades, wind, and noise designs could be added, as well as dynamic and modal analyses for completeness.

\section{References}

1. Y. Li, S. Ma, and Z. Sun, Analysis of essential meteorological elements surrounding Typhoon Sinlaku by unmanned aerial vehicle, Atmos. Clim. Sci., 6 (1), 29 (2015)

2. J. Fernández-Lozano and G. Gutiérrez-Alonso, Improving archaeological prospection using localized UAVs assisted photogrammetry: An example from the Roman Gold District of the Eria River Valley (NW Spain), J Archaeol Sci: Rep, 5, 509-520 (2016)

3. L.Wang, F. Chen, and H. Yin, Detecting and tracking vehicles in traffic by unmanned aerial vehicles, Autom. Constr., 72, 294-308 (2016).

4. Y. Cai, C. Huang, and S. Yang, An investigation of mopso and Ansys into optimizing frozen tank of fishing vessels, SNAME (Taiwan), 33 (1), 43-50 (2014)

5. Z. Gu, Y. Wu, and Y. Zhan, Dynamic balance design of CAE verification for Scroll Compressors, CSSV (Taiwan), 28-33 (2014)

6. K.B Pabitra and B. Subrata, Design and ANSYS software based simulation of U-I Type actuator and rail esed in electromagnetic levitation system, Int. J. Appl. Sci. Eng, 12 (3), 225-239 (2014)

7. L. Zhang, Y. Niu, and J. Zhou, Optimization analysis of the magnetic circuit in micro loudspeaker based on ANSYS Workbench, Electronic Design Eng., 3, 6 (2015)

8. K.H. Chen, J. Fang, and S.W. Yeh, Design of an unobtrusive reaction force measurement and its application on treadmills, IEEE Trans. Instr. Meas., 61 (7), 1955-1965 (2012)

9. A.S. Vignesh and A.Vivek, A study on fatigue fracture failure of UAV landing gear, i-Manag J. Mech Eng., 6 (1), 9 (2015)

10. S. Nallusamy, N.M. Prabu, K. Balakannan, and G. Majumdar, Analysis of static stress in an alloy wheel of the passenger car, Int. J. Eng. Res. Afr., 16, 17-25 (2015)

11. M. Ozsoy, K.Pehlivan, M. Firat; N. Ozsoy, and V. Ucar, Structural strength and fatigue life calculation of Y32 bogie frame by finite element method, Acta Phys. Polon. A, 128 (2B), B-327B-329, (2015)

12. J. Shah and J.M. Tartaglia, A case study of finite element analysis and designing with data from the AFS strain-life fatigue database, Int. J. Met., 9 (4), 7-18 (2015)

13. D. Croccolo, M. De Agostinis, and N. Vincenzi, Experimental analysis of static and fatigue strength properties in press-fitted and adhesively bonded steel-aluminium components, J Adhes Sci Technol, 25 (18), 2521-2538 (2011)

14. M. Barcaro, G. Meneghetti, and N. Bianchi, Structural analysis of the interior PM rotor considering both static and fatigue loading, IEEE Trans. Ind. Appl., 50 (1), 253-260 (2014)

15. K. Rokosz, T. Hryniewicz, W. Malorny, J. Valiček, and M. Harničárová, ANSYS analysis of stress and strain after cones plastic deformation, Tehnički vjesnik, 22 (2), 503-508 (2015)

16. Z.S. Lan, W.H. Lai, The design and application of UAV for disaster prevention, JoCICHE, Ch Civ Eng J., 27 (3), 191-199 (2015)

17. The S-N Curve. High-Cycle Fatigue. Available online: http://www.efunda.com/formulae/solid_mechanics/fatigue/fatigue_highcycle.cfm (accessed on 25 Judy 2016) 